Research Article

\title{
Numerical Simulation of Strength, Deformation, and Failure Characteristics of Rock with Fissure Hole Defect
}

\author{
Shaojie Chen, Zhiguo Xia $\mathbb{D}$, and Fan Feng \\ State Key Laboratory of Mine Disaster Prevention and Control, Shandong University of Science and Technology, \\ Qingdao 266590, China \\ Correspondence should be addressed to Zhiguo Xia; 514579197@qq.com and Fan Feng; fengfan0213@126.com
}

Received 14 May 2020; Accepted 30 July 2020; Published 17 August 2020

Academic Editor: Ivan Giorgio

Copyright (C) 2020 Shaojie Chen et al. This is an open access article distributed under the Creative Commons Attribution License, which permits unrestricted use, distribution, and reproduction in any medium, provided the original work is properly cited.

Using discrete element software, namely, particle flow code as two-dimensional program (PFC2D), two types of models were established: vertical fissure hole combination and horizontal fissure hole combination with ratios of major and minor axis of ellipse being $1,1.2,1.5,2$, and 3 , which corresponded to a total of ten samples. The failure mode, mechanical behavior, and stress state before and after crack generation in elliptical hole crack combination models with different ratios of major and minor axis were analyzed. The crack development, stress field evolution, and acoustic emission characteristics of the vertical fissure model and horizontal fissure model were studied at the optimized ratio of major and minor axis of ellipse being 1.5. The results showed that elliptical hole fissure with different ratios of major and minor axis resulted in the decrease in the strength and elastic modulus of rock and increase in the peak strain of rock. The effect of the horizontal fissure model on the peak strength, peak strain, and elastic modulus of rock was found to be greater than that of the vertical fissure hole model. Ellipses with different ratios of major and minor axis in various models slightly influenced the rock failure modes, and their failure modes corresponded to tensile shear failure and tensile failure. Before crack formation, the tensile stress concentration areas of each model were, respectively, distributed at the upper and lower ends of the vertical fissure and the major axis of ellipse, and the compressive stress concentration areas were distributed at both ends of the major axis of ellipse and the fissure in the horizontal direction. After the model failed, the compressive stress concentration areas of the vertical fissure model and the horizontal fissure model transferred to the left upper part and the right upper part of the model along the left end of the hole and the right end of the fissure, respectively. When the ratio of major and minor axis of ellipse was 1.5, cracks in the vertical model and the horizontal model of fissure developed along the axial direction at the ends of cracks and holes, respectively, and then secondary cracks were generated at the ends of left and right sides. The maximum compressive stress in each stage of the vertical fissure model was greater than that of the horizontal fissure model, and when the model was damaged, its stress release was more.

\section{Introduction}

Numerous defects such as cracks, holes, and weak structural planes are present in natural rock mass. The existence of these defects significantly influences the structural characteristics and mechanical properties of rock, and the instability and failure of rock engineering are closely related to the crack initiation and extension characteristics of fissure and holes in rock [1-6]. Therefore, in-depth study on the failure characteristics and mechanical properties of defective rocks is of great significance for the comprehensive understanding of the stability and safety of rock engineering.
For a long time, extensive research efforts have been devoted to the study of the defects in rocks such as fissure and holes [7, 8]. For example, Li and Wong [9] adopted finite element method (FEM) and nonlinear dynamics method to study the effect of crack dip on the crack propagation process through finite element analysis of the stress field distribution in the presence of cracks. Bobet and Einstein [10] studied the fissure coalescence behavior of brittle materials by uniaxial and biaxial compression tests on specimens containing two preexisting fissures with gypsum as rock model material. Furthermore, to analyze the fracture coalescence behavior of rock, Yang et al. [11] conducted uniaxial compression test on 
rectangular prismatic sandstone specimens containing three fissures; studied the influence of ligament angle on the peak strength, peak strain, and crack initiation stress of specimens; and finally analyzed their strength and deformation behavior. Cao et al. [12] combined similar material tests with discrete element numerical method, namely, particle flow code as two-dimensional program (PFC2D), to explore the peak strength and failure characteristics of the premade multifissure rock-like materials. Wong et al. [13] conducted a series of uniaxial compression physical and numerical tests on single-hole samples with different diameters and sample widths and further studied the splitting failure, failure mode, and strength characteristics of samples caused by crack propagation. Huang et al. [14] carried out uniaxial compression test and numerical simulation study on granite samples containing three noncoplanar holes; analyzed the relationship between stress, acoustic emission (AE), and crack propagation process via $\mathrm{AE}$ measurement and image monitoring technology; and determined four typical crack coalescence modes. Lin et al. [15] studied the crack initiation, coalescence mechanism, and failure behavior of porous granite under uniaxial compression by changing the hole spacing and number of holes in the specimen and proposed the coalescence mechanism criterion related to the hole distribution.

Moreover, with respect to the combination defects of ellipse and fissure hole, scholars have also carried out relevant related research. For example, Yang et al. [16] adopted two-dimensional (2D) particle flow numerical simulation and experimental methods to study the strength, deformation, and crack evolution behavior of sandstones with single elliptical holes under uniaxial compression. Han et al. [17] conducted a series of dynamic impact tests on a doubleelliptical cracked sandstone specimen with a diameter of $75 \mathrm{~mm}$ to evaluate the effect of cracks with different geometric sizes on the dynamic strength, deformation characteristics, and fissure evolution of rock materials. Li et al. [18] conducted a uniaxial compression test on a preexisting set of fractured elliptical combinations of marble types and studied the crack propagation and coalescence behavior in the specimen and the $\mathrm{AE}$ characteristics of presplitting marble samples. Furthermore, Liu et al. [19] used AE monitoring and digital image correlation system to study the strength and fissure mechanism of the defective rocks containing two sets of crack ellipse combination and then determined four rock bridge coalescence modes by analyzing the limit failure modes. Feng et al. [20] used the commercial combined FEM/discrete element method (DEM) to study the failure characteristics and crack propagation process of typical hard rock specimen (marble) in the unloading process of five different shapes of center hole and analyzed the crack propagation path and strain energy release around the center hole, etc. Zhu et al. [21] used a numerical code called rock failure process analysis to simulate the progressive failure process around three common shapes of underground excavation, namely, circular, elliptical, and inverted $U$-shaped holes; predicted the fracturing mode under different loading conditions; and determined the failure mechanism under different loading conditions.
The above-mentioned studies mainly focused on fracture, hole defect, and other defects. However, in actual engineering, the interior of rock material is very complex, usually containing various defects such as fissure and holes of different sizes [22, 23], as shown in Figure 1. Moreover, the interaction between these combined defects may lead to rock instability and failure. Nonetheless, the interaction mechanism between combined defects with fissure holes has not been fully understood $[24,25]$. For the comprehensive understanding of the strength and failure behavior of rock materials with fissure holes, this study investigated the deformation characteristics, force chain distribution, and stress field evolution of rocks with the combination of vertical fissure ellipse and horizontal fissure ellipse by changing the ratio of major and minor axis of ellipse (changing the ratio of major and minor axis of ellipse is equivalent to changing the area of ellipse).

\section{Model Establishment and Parameter Determination}

2.1. Particle Flow Code. Cundall and Strack proposed the DEM in 1971 [26]. Rigid particles are commonly used in discrete element to represent physical objects, and rigid wall is used as the boundary of the model. DEM simulates the movement and interaction of particles. The particles of rigid bodies can be both translational and rotational. The force and displacement between particles are achieved through contact. The contact bonds (CB) and parallel bonds (PB) in $\mathrm{PFC}$ can be used to simulate the connection between rock particles, the $\mathrm{CB}$ can only transfer the force between units, and the $\mathrm{PB}$ can transfer not only the force, but also the moment $[27,28]$, as shown in Figure 2. When the maximum tensile stress of the $\mathrm{PB}$ between the contact particles exceeds the tensile strength of the bond or the maximum shear stress exceeds the shear strength of the bond, the bond gets broken and the force and moment of the PB also disappear. Considering that the $\mathrm{PB}$ model can transmit forces and moments, it is more suitable for simulating rocks than the $\mathrm{CB}$ model which can only transmit forces and can better simulate the formation and propagation process of real rock cracks. Moreover, the failure of rock belongs to discontinuous deformation, and thus PFC can well solve and study discontinuous problems. In this study, the uniaxial compression model of the specimen with fissure holes was established using the method of parallel bonding.

2.2. Particle Flow Code Analog Acoustic Emission. In general, after the rock numerical model is established, the normal and tangential bond strength of the model can directly reflect the macro strength of the rock. Under the influence of external load, when the stress transmitted between the particles exceeds the bond strength between the particles, the bond between the particles breaks, causing the generation of microcracks in the rock sample [29]. Further, when microcracks propagate in rock specimens, damage energy is rapidly released in the form of acoustic waves, which corresponds to the $\mathrm{AE}$ phenomenon [30,31]. Therefore, AE 


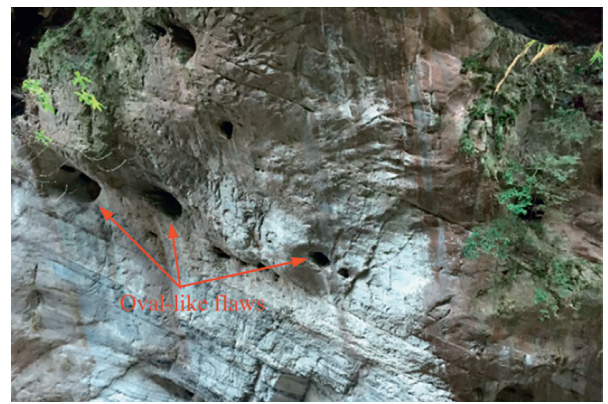

Figure 1: Rock mass containing preexisting oval-like flaws [22].
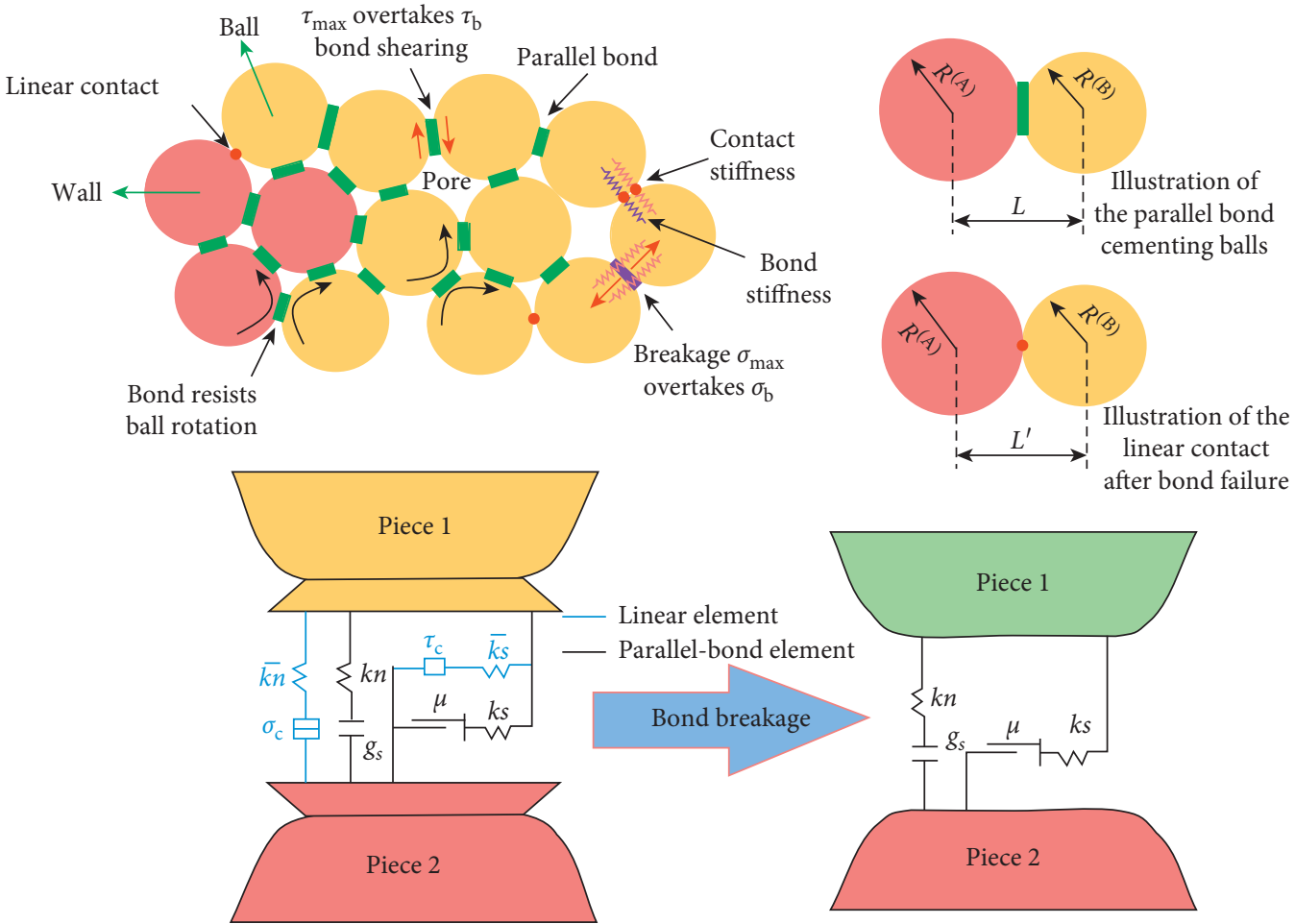

Figure 2: Parallel bond model.

events can be simulated by calculating the number of bond fractures of particles in the process of numerical experiments. Owing to the limitation of calculation ability, the particle size and number of PFC2D cannot directly reach the level of mechanical response to real macro rock; however, the mechanical laws reflected are helpful to understand the AE phenomenon of rock [32].

2.3. Determination of Parameters. When PFC2D is used for numerical simulation test, the microscopic parameters of particles are very important. However, these microscopic parameters cannot be directly obtained from laboratory tests. Therefore, it is necessary to check the microscopic parameters in order to ensure that the numerical simulation results are consistent with the laboratory test results [33]. First, the basic mechanical parameters of rock are obtained through a large number of laboratory tests, and then the numerical simulation results are compared with the laboratory test results. Furthermore, the microparameters are adjusted repeatedly through the "trial and error method" until the requirements of the simulation analysis are completely met. The results of laboratory tests and numerical tests were compared as shown in Figure 3.

2.4. Establishment of the Numerical Model. In order to study the influence of ellipses and fissure defects with different ratios of major and minor axis on rock failure and mechanical behavior, two types of models were established: vertical fissures and horizontal fissures vertically intersecting the major axis of the ellipse, which were respectively called vertical fissure hole model and horizontal fissure hole model, as shown in Figure 4(a). The ratio of major and minor axis of each model was set as $1,1.2,1.5,2,3,5$, and 10 , and the corresponding models were established. Among them, the size of the major axis remained unchanged, and the ratio of major and minor axis was determined by changing the 

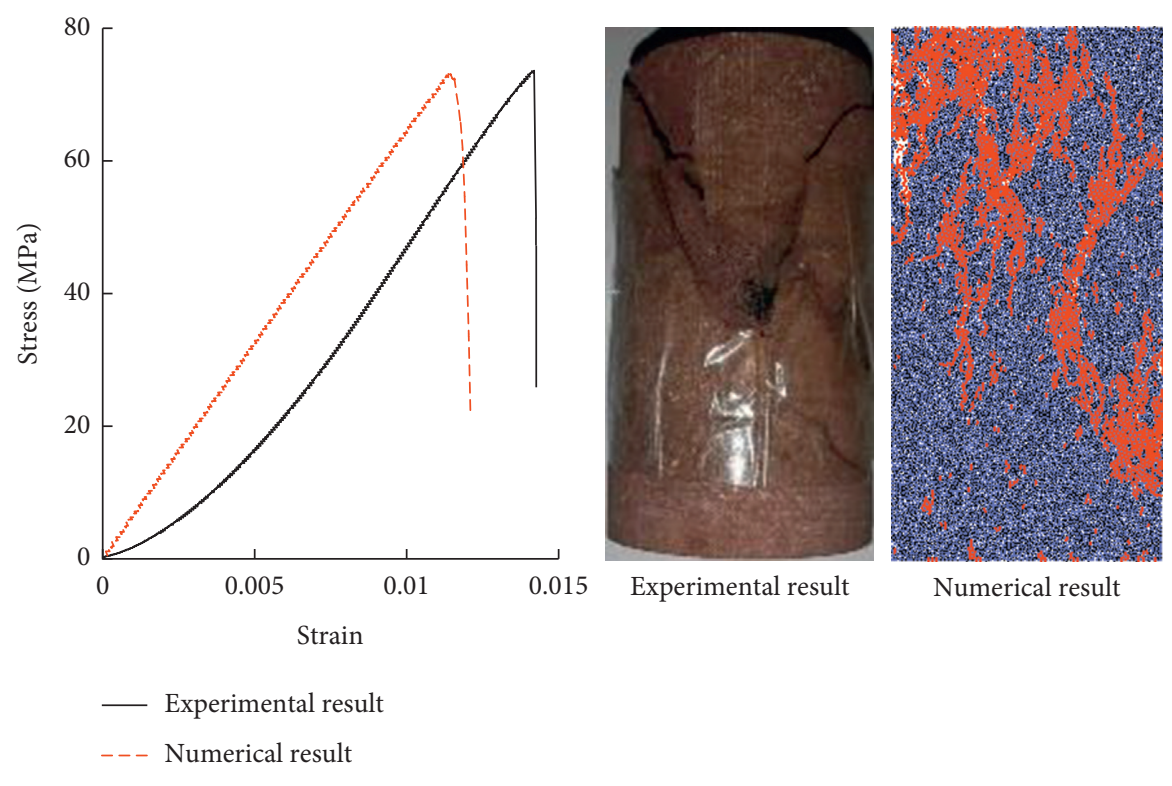

Figure 3: Calibration of numerical parameters.
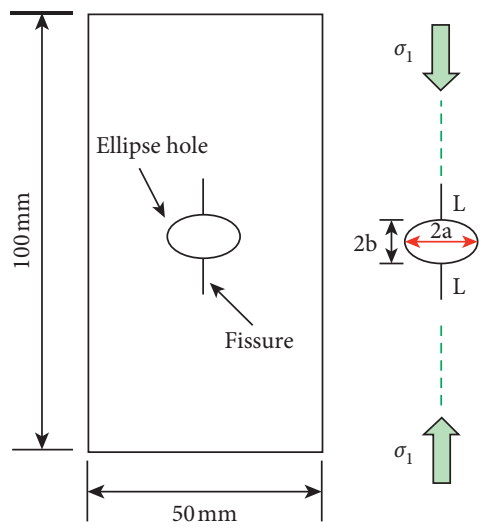

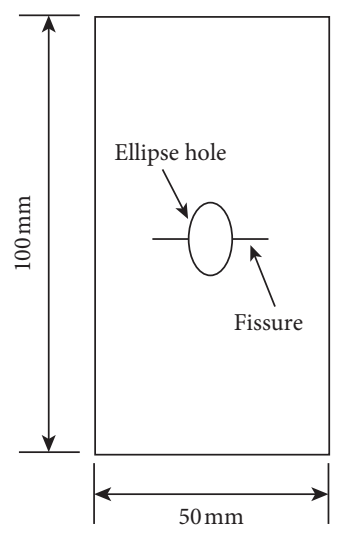

(a)
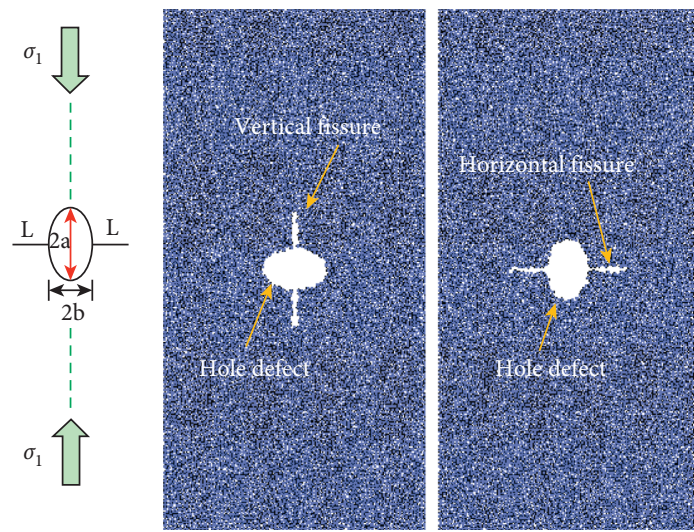

(b)

FiguRE 4: Schematic illustration and numerical model illustration of hole fissure defects. (a) Schematic illustration. (b) Numerical model illustration.

length of the minor axis. The hole areas corresponding to different ratios of major and minor axis were, respectively, about $452,377,301,226$, and $151 \mathrm{~mm}^{2}$. In this study, different ratios of major and minor axis were used for investigation. The height of the model was $100 \mathrm{~mm}$, the width was $50 \mathrm{~mm}$, the major axis $2 \mathrm{a}$ of the ellipse was $12 \mathrm{~mm}$, the minor axis of the ellipse was $2 \mathrm{~b}$, the longest axis of the ellipse was $12 \mathrm{~mm}$ and the shortest axis was $4 \mathrm{~mm}$, and the length of the fissure was determined according to the length of the minor axis of the ellipse. The sum of the total length of the two fissures was at least $10 \mathrm{~mm}$ and at most $18 \mathrm{~mm}$, and the sum of the total length of the two fissures and the minor axis of the ellipse was always $22 \mathrm{~mm}$. The details about the specific size of the model are presented in Table 1. According to the size presented in Table 1, the particles of ellipse and fissures were deleted to build a numerical model, as shown in Figure 4(b).

A Shimadzu AG-X250 precision universal testing machine was used as the loading system, and it was used for performing regular compression and tensile tests. Displacement-based loading control method was used to perform the uniaxial compression test until the sample fractured. The loading rate was set to $0.01 \mathrm{~mm} / \mathrm{s}$. All the tests were conducted according to ISRM standards (Brown 1981). The numerical model was loaded based on displacement loading, the loading rate was $0.01 / \mathrm{s}$, the bottom of the sample was fixed, and the left and right sides were released.

The numerical simulation and laboratory testing of the stress-strain curve and failure mode of combination defects of ellipse and fissure hole are shown in Figure 5. The stressstrain curves of both the models are basically consistent, and the macroscopic failure characteristics of actual rock samples are similar to those of numerical samples.

Table 2 summarizes the comparison of strength and deformation parameters of sandstone samples between laboratory test and numerical test. In the vertical fissure model, the difference in the peak strength, elastic modulus, 
TABle 1: Size parameters of elliptic fissure hole model with different ratios of major and minor axis.

\begin{tabular}{|c|c|c|c|c|c|c|}
\hline Type & Number & Height (mm) & Length $(\mathrm{mm})$ & $2 \mathrm{a}(\mathrm{mm})$ & $2 \mathrm{~b}(\mathrm{~mm})$ & $L(\mathrm{~mm})$ \\
\hline \multirow{5}{*}{ Vertical fissure model } & (1) & 100 & 50 & 12 & 12 & 5 \\
\hline & (2) & 100 & 50 & 12 & 10 & 6 \\
\hline & (3) & 100 & 50 & 12 & 8 & 7 \\
\hline & (4) & 100 & 50 & 12 & 6 & 8 \\
\hline & (5) & 100 & 50 & 12 & 4 & 9 \\
\hline \multirow{5}{*}{ Horizontal fissure model } & (6) & 100 & 50 & 12 & 12 & 5 \\
\hline & (7) & 100 & 50 & 12 & 10 & 6 \\
\hline & (8) & 100 & 50 & 12 & 8 & 7 \\
\hline & (9) & 100 & 50 & 12 & 6 & 8 \\
\hline & (10) & 100 & 50 & 12 & 4 & 9 \\
\hline
\end{tabular}
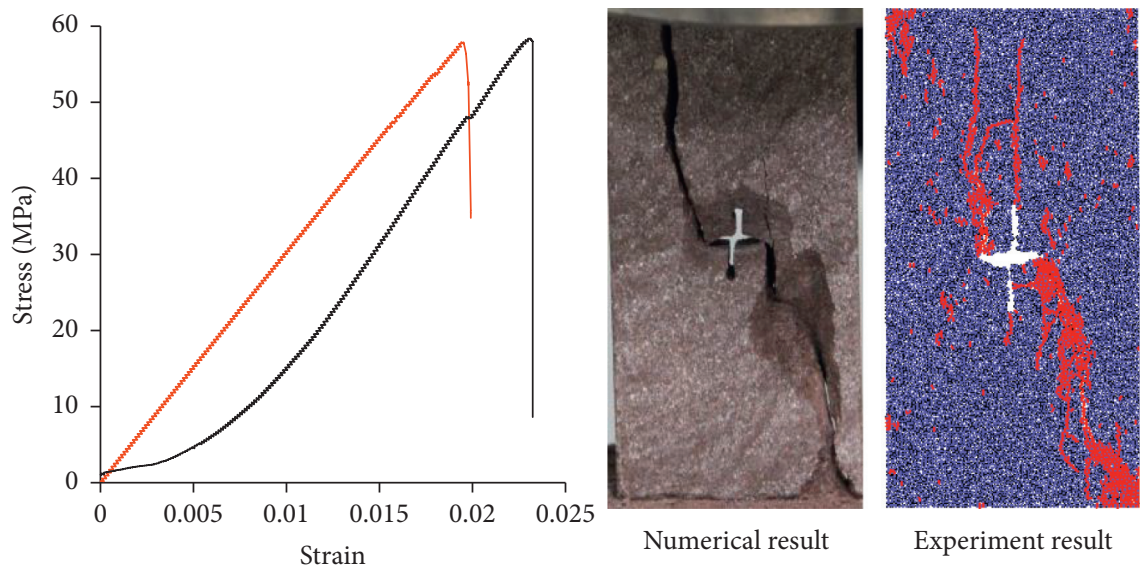

- Numerical result

— Experiment result

(a)
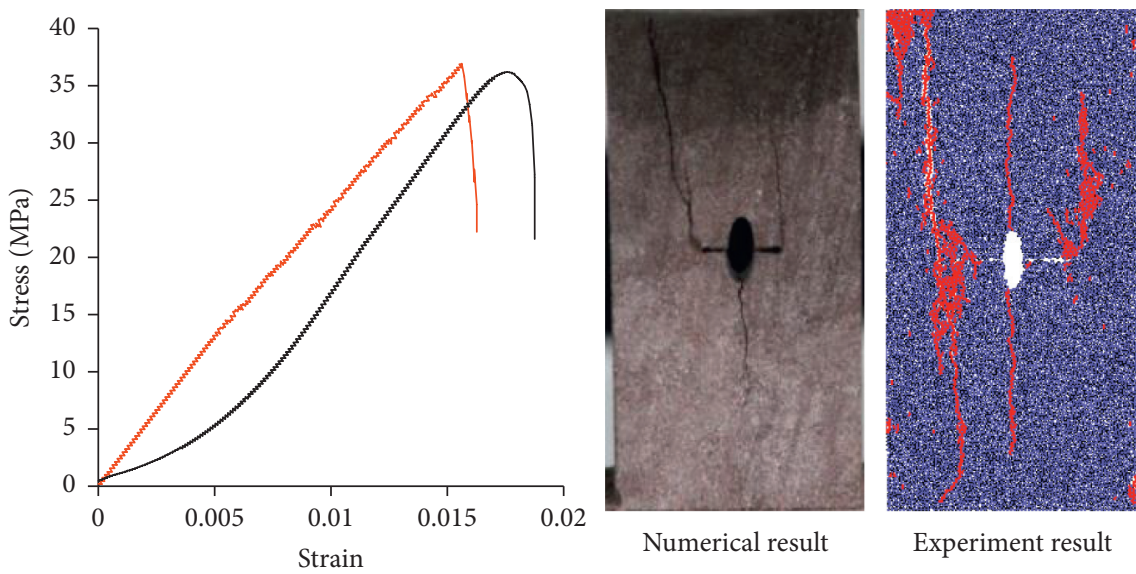

— Numerical result

_ Experiment result

(b)

FIGURE 5: Comparison between numerical simulation results and test results. (a) Vertical fissure model. (b) Horizontal fissure model.

TABLE 2: Comparison of mechanical properties between laboratory test results and numerical simulation results.

\begin{tabular}{|c|c|c|c|c|c|c|}
\hline \multirow{2}{*}{ Category } & \multicolumn{3}{|c|}{ Vertical fissure model $(\mathrm{a} / \mathrm{b}=3)$} & \multicolumn{3}{|c|}{ Horizontal fissure model $(\mathrm{a} / \mathrm{b}=3)$} \\
\hline & Peak stress $(\mathrm{MPa})$ & Elastic modulus (GPa) & Peak strain & Peak stress $(\mathrm{MPa})$ & Elastic modulus (GPa) & Peak strain \\
\hline Experiment result & 58.37 & 1.567 & 0.0231 & 36.19 & 1.233 & 0.0176 \\
\hline Numerical result & 56.98 & 1.316 & 0.0196 & 36.93 & 1.035 & 0.0157 \\
\hline Error $(\%)$ & 2.38 & 16.02 & 15.15 & 2.0 & 16.05 & 10.8 \\
\hline
\end{tabular}


and peak strain between the real rock test and the numerical test is about $2.38,16.02$, and $15.15 \%$, respectively. In the horizontal fissure model, the differences in peak strength, elastic modulus, and peak strain between real rock and numerical test are about 2.0, 16.05, and $10.8 \%$, respectively. The result indicated that the strength and deformation parameters of numerical experiment and real rock samples were in good agreement with each other, thus reflecting the strength and deformation characteristics of rock.

\section{Analysis of Test Results}

3.1. Influence of Vertical Fissure Holes and Horizontal Fissure Holes with Different Ratios of Major and Minor Axis of Ellipse on Rock Mechanical Properties. Figure 6 shows the stressstrain curve and crack number-strain curve of the vertical and horizontal fissure hole models with different ratios of major and minor axis of ellipse. Figure 6 demonstrates that the stress-strain curve of the fissure hole model can be divided into the following three stages: elastic stage, plastic stage, and failure stage. Compared to the real rock, there is a lack of compaction stage, which is attributed to the fact that the particles in PFC are rigid bodies, and the model bond is not damaged in the initial loading stage. The postpeak curve indicates that the failure of fissure hole rock basically becomes brittle failure. The influence of elliptical holes with different ratios of major and minor axis on the strength of rock model is different. Moreover, the comparative analysis indicates that the influence of horizontal fissure holes on the strength of rock model is greater than that of vertical fissure holes. Furthermore, the crack number-strain curve demonstrates the three stages experienced during the crack development: no crack, slow crack growth, and fast crack growth. The strain (0.012) when the crack is generated in the vertical fissure hole model is greater than the strain (0.005) when the crack is generated in the horizontal fissure hole model, which indicates that the crack in horizontal fissure hole model is generated prior to that in vertical fissure hole model.

Figure 7 shows the peak strength, peak strain, and elastic modulus of the vertical fissure hole model and the horizontal fissure hole model with different ratios of major and minor axis of ellipse. The maximum peak strength in the fissure vertical hole model is approximately $58.5 \mathrm{MPa}$, the minimum peak strain is approximately 0.0186 , and the maximum elastic modulus is approximately $1.32 \mathrm{GPa}$. Moreover, the maximum peak strength in the horizontal fissure hole model is approximately $36.9 \mathrm{MPa}$, the minimum peak strain is around 0.0144 , and the maximum elastic modulus is about $1.04 \mathrm{GPa}$. Figure 3 and Table 3 reveal that the peak strength of intact rock is about $73 \mathrm{MPa}$, the peak strain is about 0.0115 , and the elastic modulus is about $3.19 \mathrm{GPa}$. The peak strength and elastic modulus of the vertical fissure hole model and the fissure horizontal hole model are both lower than those of the intact rock sample. The values of peak strength of both models are at least 19.8 and $49.5 \%$ lower than that of intact rock, respectively, and the elastic modulus is reduced by at least 58.6 and $67.4 \%$, respectively, while the peak strain is higher than that of the intact rock sample. This shows that both the vertical fissure hole model and horizontal fissure hole model significantly influence the mechanical properties of rock, with the horizontal fissure hole having greater influence on the mechanical properties of rock.

The peak strength, peak strain, and elastic modulus of the vertical fissure hole model were found to be larger than those of the horizontal fissure hole model on the whole. Moreover, the peak strength, peak strain, and elastic modulus of the vertical fissure hole model with the same ellipse major and minor axis ratio are also larger than those of the horizontal fissure hole model; nonetheless, the trends of the peak strength, peak strain, and elastic modulus of the two models are basically the same. The peak strength and peak strain of the two models show an increasing trend first and then a decreasing one followed by again increasing. The maximum is when major and minor axis ratio is 1.2, and the minimum is when major and minor axis ratio is 1.5; however, the elastic modulus is basically the same. It shows that ellipses with different major and minor axis ratios have different effects on the strength and peak strain of rocks but have little effect on elastic modulus.

3.2. Failure Modes of Vertical Fissure Hole Model and Horizontal Fissure Hole Model with Different Ellipse Major and Minor Axis Ratios. Figure 8 exhibits the final failure mode of specimens with elliptical fissure holes with different major and minor axis ratios under uniaxial compression. The change of ellipse major and minor axis ratios has no obvious influence on the failure mode of the rock sample; however, the existence of fissures obviously influences the failure mode of the rock sample. Through comparative analysis, the failure modes of specimens with fissure elliptical holes can be divided into the following two types:

(1) Tensile shear mixed failure: the failure modes of all specimens in the vertical fissure model with different major and minor axis ratios of ellipse and the horizontal fissure model specimens with ellipse major and minor axis ratios of 1.2 and 2.0 correspond to tensile shear mixed failure. Cracks causing instability of specimens in the vertical fissure model and the horizontal fissure model mainly start at the end points of the major axis of ellipses and at the left and right end points of horizontal fissure, respectively. The shear fissure surface penetrates the rock sample along the diagonal direction; however, in the fissure vertical model and the fissure horizontal model, cracks from the two tips of vertical fissure and the upper and lower ends of ellipses penetrate to the end points of the rock sample approximately axially. The tensile shear failure of the vertical fissure model was more obvious than that of the horizontal fissure model; however, the specimen failure of the vertical fissure model was more obvious.

(2) Tensile failure: when the ratio of major and minor axis of ellipse in the horizontal fissure model is 1, 1.5, and 3.0, the rock sample eventually undergoes tensile 


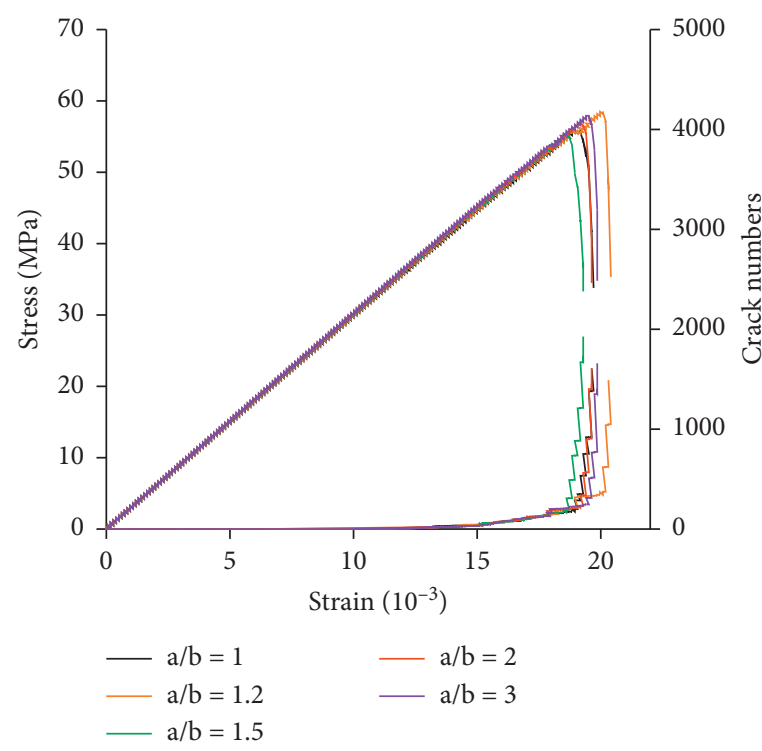

(a)

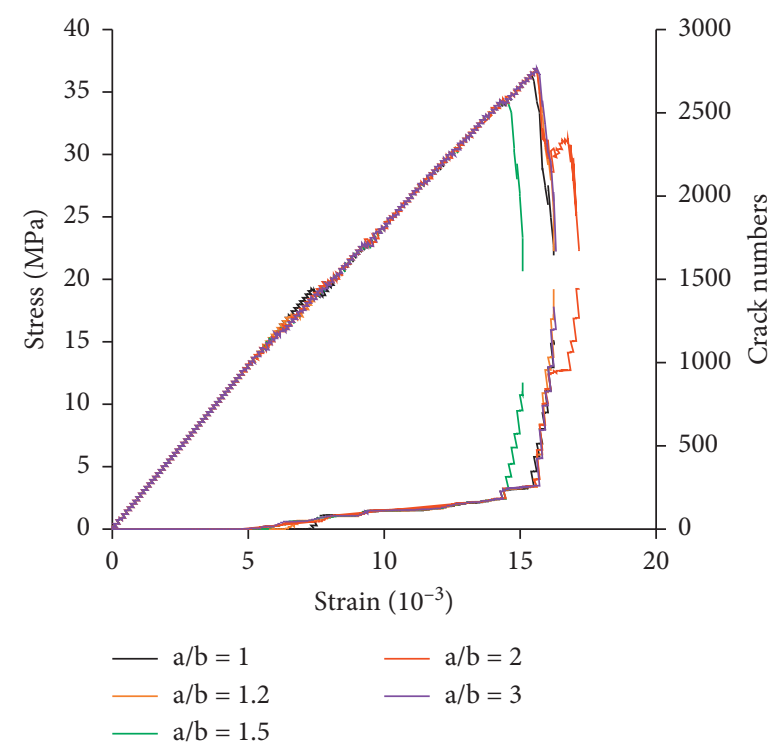

(b)

FIGURE 6: The stress-strain curve and crack number-strain curve. (a) Vertical fissure stress-strain curve and crack number-strain curve. (b) Horizontal fissure stress-strain curve and crack number-strain curve.

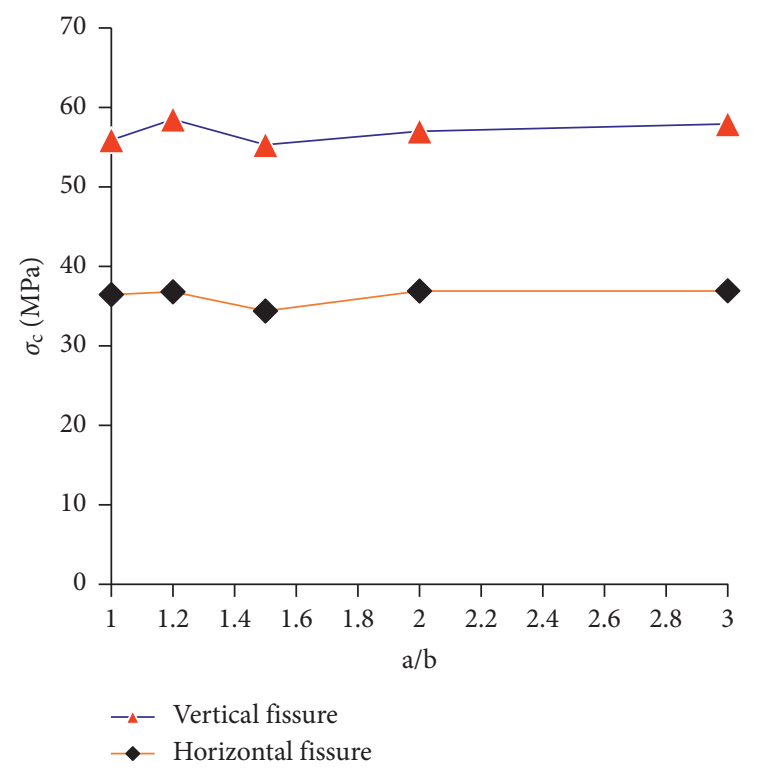

(a)

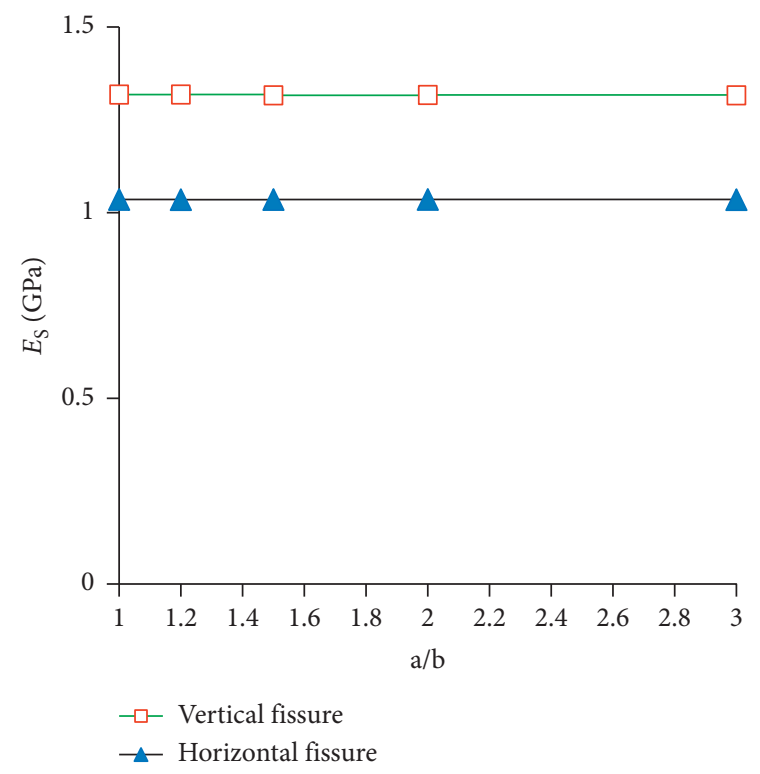

(b)

Figure 7: Continued. 


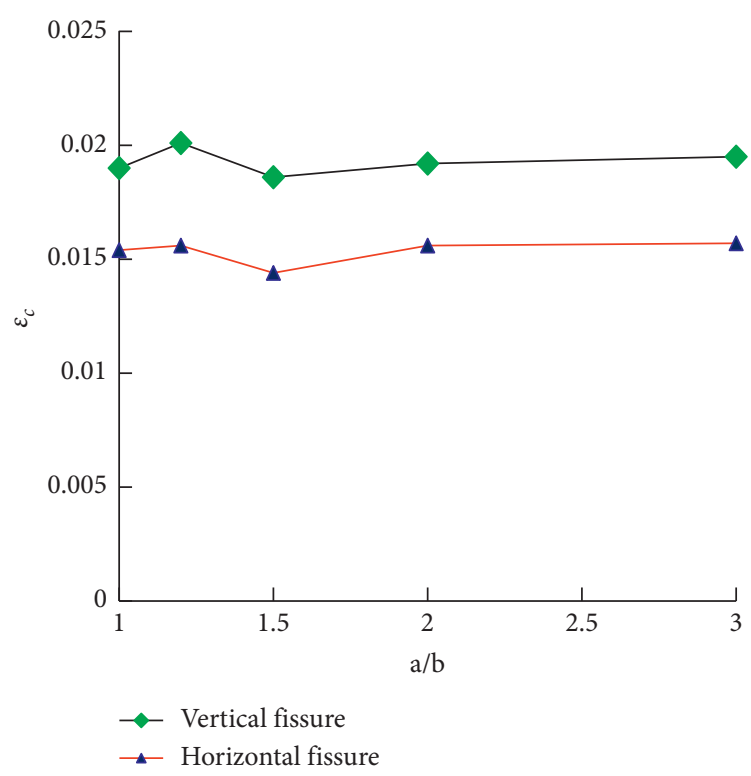

(c)

Figure 7: Mechanical parameters of fissure holes under uniaxial compression.

TABLE 3: Mechanical parameters of sandstone model based on PFC.

\begin{tabular}{lc}
\hline Parameter & Value \\
\hline Minimum particle diameter $(\mathrm{mm})$ & 0.3 \\
Particle diameter ratio & 1.5 \\
Density $\left(\mathrm{kg} / \mathrm{m}^{3}\right)$ & 2490 \\
Contact modulus of the particle $(\mathrm{GPa})$ & 3.19 \\
Contact bond gap $(\mathrm{mm})$ & 0.05 \\
Porosity & 0.1 \\
Parallel bond friction angle $\left(^{\circ}\right)$ & 38 \\
Parallel bond tensile strength $(\mathrm{MPa})$ & 22.3 \\
Normal critical damping ratio & 0.5 \\
Parallel bond cohesive force $(\mathrm{MPa})$ & 33 \\
\hline
\end{tabular}

failure, and the cracks that eventually cause instability of the rock sample mainly start at the left and right ends of the fissure and at the upper and lower ends of the hole, which are approximately distributed in a " $Y$ " shape.

Figure 9 shows the number of cracks when the vertical fissure and horizontal fissure models failed. The figure indicates that the number of cracks in the fissure vertical model with different ratios of major and minor axis of ellipse is greater than that in the horizontal fissure model. In the vertical fissure model, the number of cracks tends to decrease-increase-decrease-increase with the increase in the ratio of major and minor axis, while the cracks in the horizontal fissure model tend to increase-decrease-increase-decrease. When the ratio of major and minor axis of ellipse is 1.5 , the crack number of the vertical fissure hole model is the maximum, while that of the fissure horizontal hole model is the minimum, which indicates that the damage degree of the vertical fissure model when the ratio of major and minor axis of ellipse is 1.5 , is more serious than that of the horizontal fissure model, which can be seen from the final damage illustration shown in Figure 8.

\subsection{Force Chain, Crack Propagation, and Stress Evolution before Crack Formation and after Failure}

3.3.1. Force before and after Crack Formation. Table 4 presents the force chain illustration before crack generation and after failure of models with different ratios of major and minor axis of ellipse when the crack is vertical and horizontal. The black lines represent compressive stress and the red lines represent tensile stress. Columns (a) and (c) in Table 4 correspond to force chain illustrations before crack generation. The illustrations clearly indicate that areas 1, 2, 3, and 4 are areas with relatively dense tensile stress, which are approximately distributed in a butterfly shape. However, areas with concentrated tensile stress are distributed at the upper and lower ends of vertical cracks in column (a) of Table 4 and areas circled in blue ellipses in column (c) Table 4. In Table 4, the areas $\mathrm{a}$ and $\mathrm{b}$ are areas with relatively dense compressive stress, which are mainly distributed on the left and right sides of the fissure hole (the area surrounded by the green ellipse is the area of compressive stress concentration). A stress triangular area is present near the crack end or the hole end in the vertical direction, the opening of the triangular area is a tensile stress concentration area, and a smaller stress reduction area is present near the tip of the triangular area. The illustrations presented in columns (a) and (c) of Table 4 reveal that, irrespective of the fissure being vertical or horizontal, the compressive stress concentration area is distributed on the left and right sides of the fissure hole in the horizontal direction, and the tensile stress is distributed on the upper and lower ends of the fissure hole in the vertical direction. The compressive stress concentration range in the vertical fissure model is obviously larger than that in the fissure horizontal model; however, the tensile stress concentration range and stress decreasing range are smaller than those in the horizontal fissure model. With the gradual increase in the ratio of major and minor axis, the 


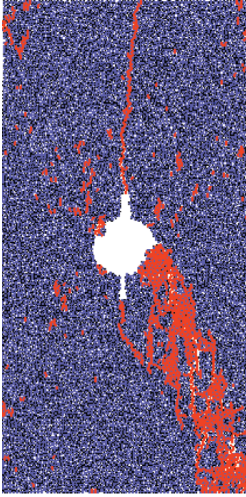

$\mathrm{a} / \mathrm{b}=1$

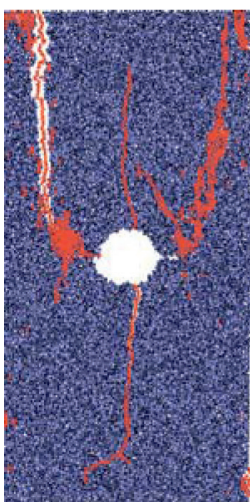

$\mathrm{a} / \mathrm{b}=1$

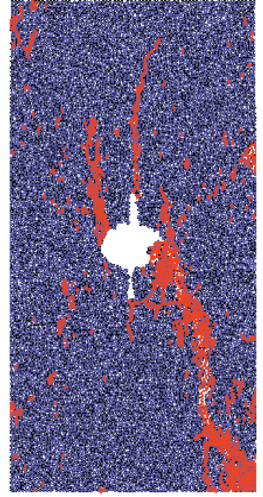

$\mathrm{a} / \mathrm{b}=1.2$

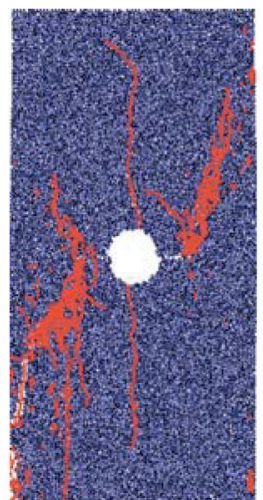

$\mathrm{a} / \mathrm{b}=1.2$

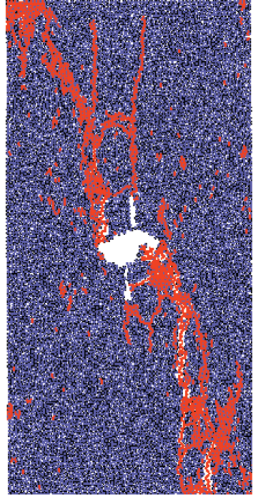

$\mathrm{a} / \mathrm{b}=1.5$

(a)

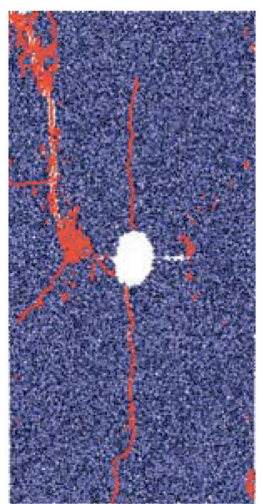

$\mathrm{a} / \mathrm{b}=1.5$

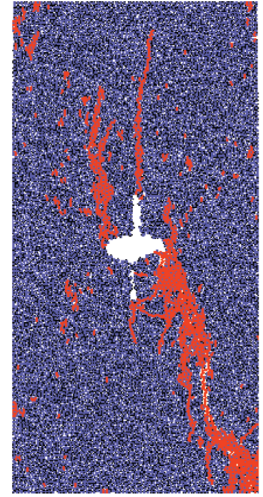

$\mathrm{a} / \mathrm{b}=2.0$

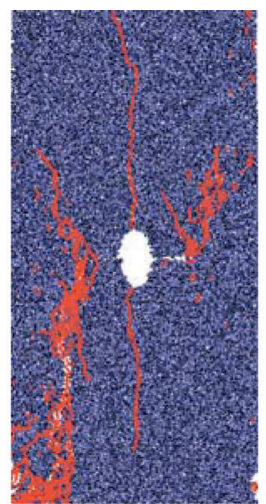

$\mathrm{a} / \mathrm{b}=2.0$

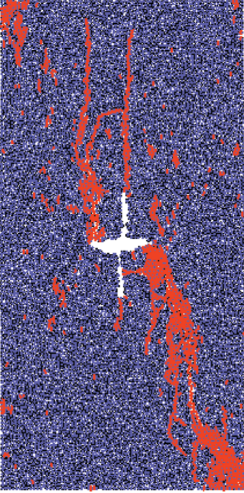

$\mathrm{a} / \mathrm{b}=3.0$

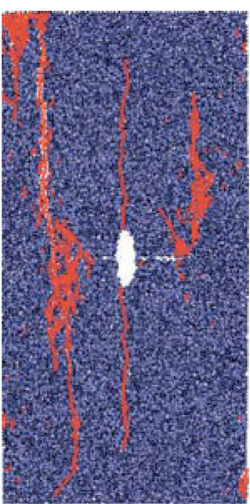

$\mathrm{a} / \mathrm{b}=3.0$

(b)

Figure 8: Final failure illustration of model. (a) Fissure vertical model with different ratios of major and minor axis of ellipse. (b) Horizontal fissure model with different ratios of major and minor axis of ellipse.

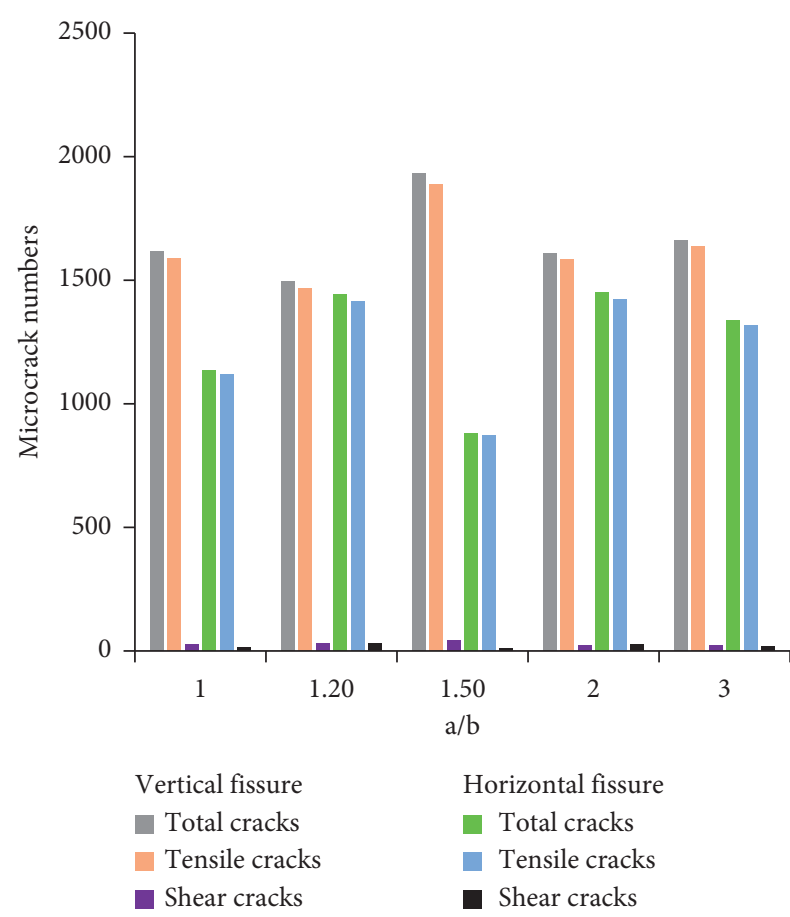

FIgURE 9: Final crack number after model failure. concentration range of compressive stress and tensile stress in each model decreases gradually. Columns (b) and (d) of Table 4 show the final failure illustrations of the vertical and horizontal fissure models. The compressive stress concentration area of the vertical fissure model is distributed on the left side of the fissure hole; however, that of the horizontal fissure model is distributed on the right side of the fissure hole. With the increase of the ratio of major and minor axis, the range of compressive stress concentration in the final failure of the model increases gradually.

In Table 4, areas 1, 2, 3, and 4 are areas with dense distribution of tensile stress; areas $a$ and $b$ are areas with dense distribution of compressive stress; and areas circled in green ellipses are areas with concentrated compressive stress. The tip of the triangular area in the vertical direction is the stress decreasing zone, and the blue ellipse circled areas at the upper and lower ends of cracks and holes are the tensile stress concentration areas.

3.3.2. Crack Propagation and Stress Evolution. Based on the results of the large number of models studied, one of the five types of ratios of major and minor axis was selected as the optimized research value (i.e., the ratio of major and minor axis of 1.5). Figures 10 and 11, respectively, exhibit the crack 
TABLE 4: Force chain diagram before crack generation and after failure.

Vertical fissure model

(a)

Before crack formation

Compression
Tension

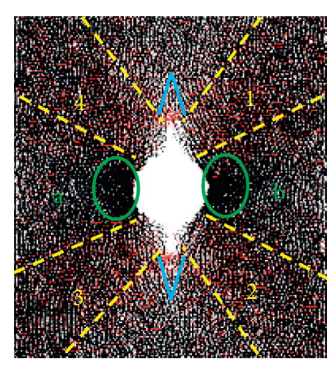

$a / b=1$

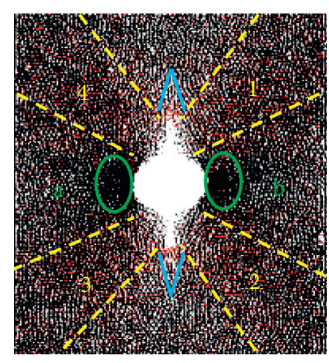

$\mathrm{a} / \mathrm{b}=1.2$

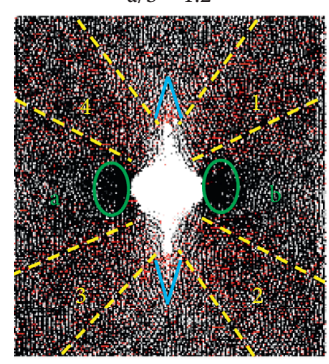

$\mathrm{a} / \mathrm{b}=1.5$

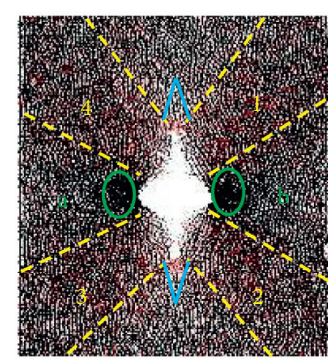

$\mathrm{a} / \mathrm{b}=2.0$

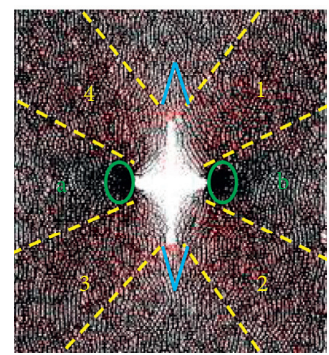

$\mathrm{a} / \mathrm{b}=3.0$ (b)

After specimen failure
$\begin{aligned} & \text { Compression } \\ & \text { Tension }\end{aligned}$

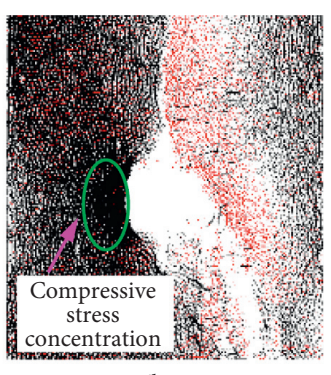

$\mathrm{a} / \mathrm{b}=1$

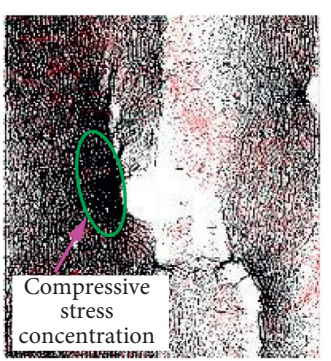

$\mathrm{a} / \mathrm{b}=1.2$

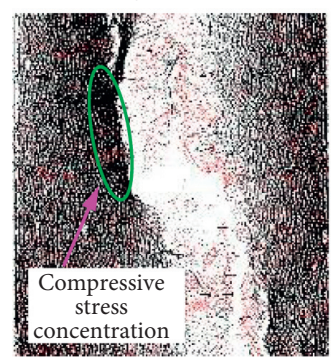

$\mathrm{a} / \mathrm{b}=1.5$

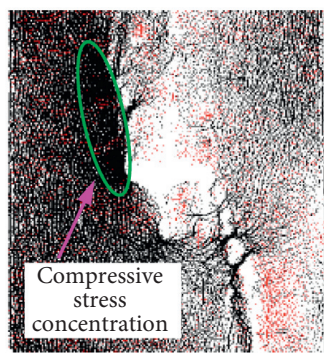

$\mathrm{a} / \mathrm{b}=2.0$

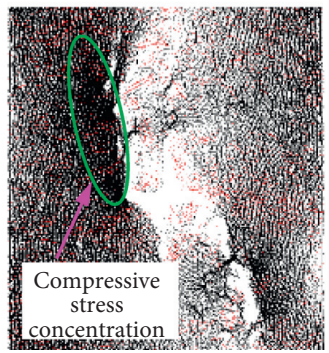

$\mathrm{a} / \mathrm{b}=3.0$ (c)

Before crack formation

Compression
Tension

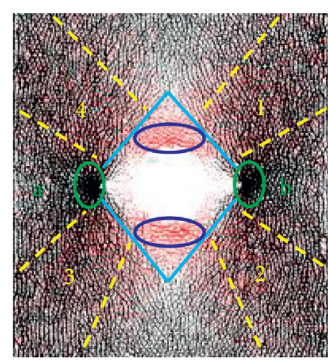

$\mathrm{a} / \mathrm{b}=1$

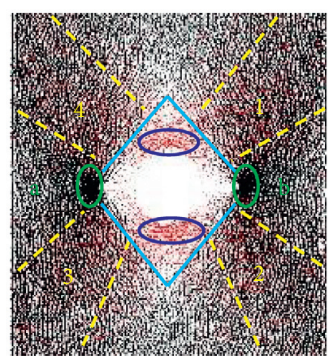

$a / b=1.2$

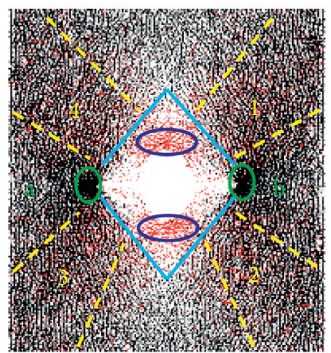

$\mathrm{a} / \mathrm{b}=1.5$

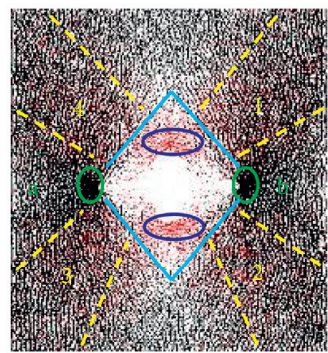

$\mathrm{a} / \mathrm{b}=2.0$

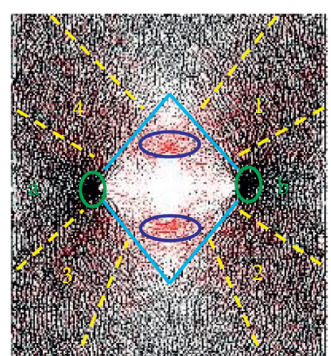

$a / b=3.0$ (d)

After specimen failure

Compression

Tension

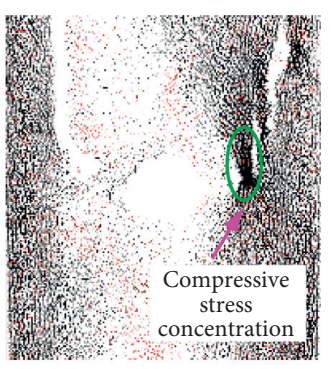

$\mathrm{a} / \mathrm{b}=1$

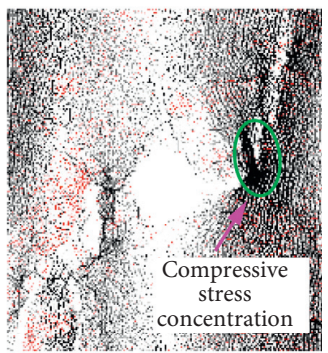

$\mathrm{a} / \mathrm{b}=1.2$

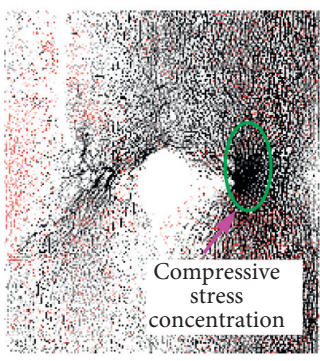

$\mathrm{a} / \mathrm{b}=1.5$

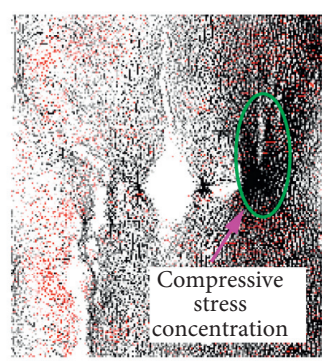
$\mathrm{a} / \mathrm{b}=2.0$

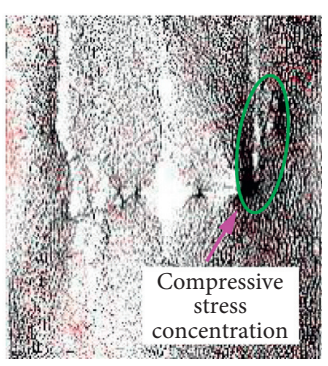
$\mathrm{a} / \mathrm{b}=3.0$ 

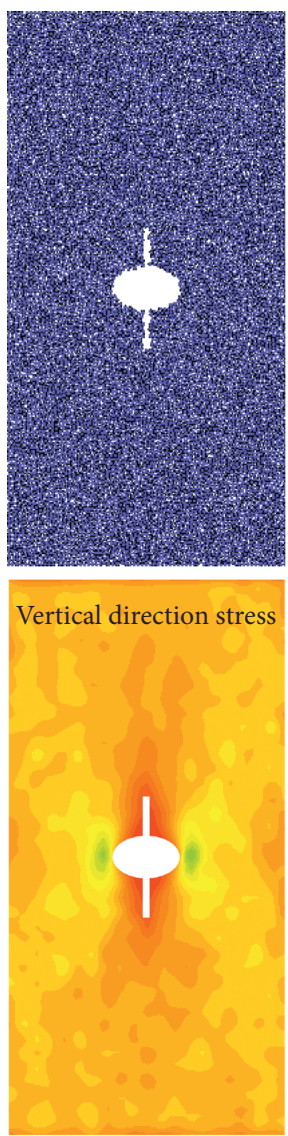

Strain $9.44 / 10^{3}$

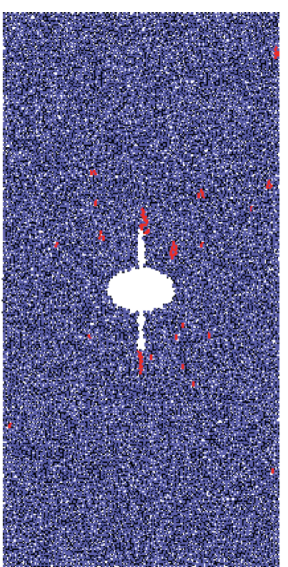

Vertical direction stress

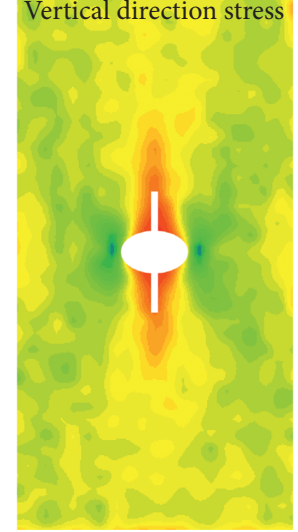

Strain $15.31 / 10^{3}$
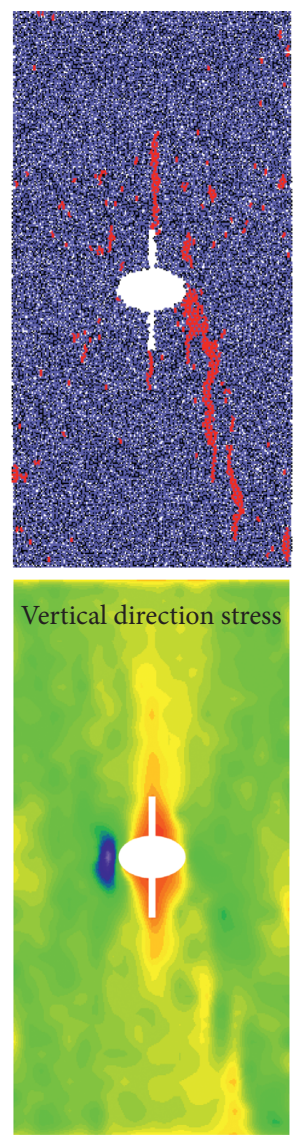

Strain $18.86 / 10^{3}$
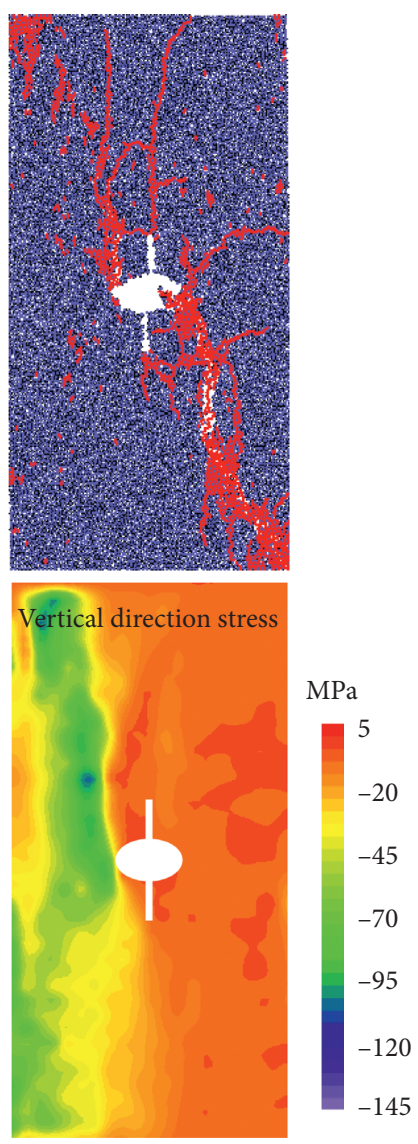

Strain $19.28 / 10^{3}$

FIGURE 10: Crack propagation and maximum principal stress illustration when the major and minor axis ratio a/b $=1.5$ of vertical fissure ellipse.

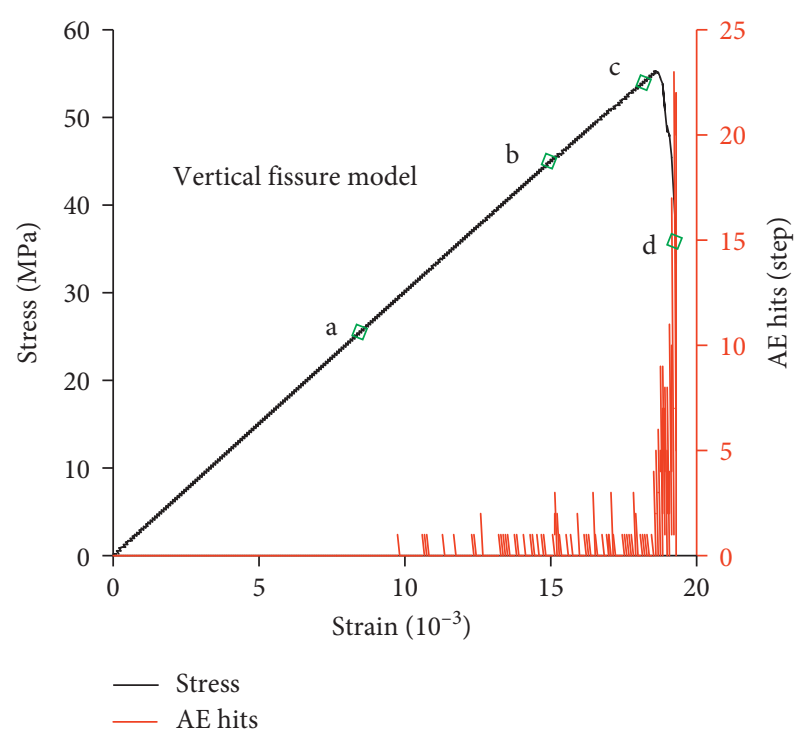

Figure 11: Stress-strain curve and acoustic emission-strain curve when the major and minor axis ratio $\mathrm{a} / \mathrm{b}=1.5$ of vertical fissure ellipse.

propagation and maximum principal stress evolution illustration, stress-strain curve, and AE-strain curve of the vertical fissure model for the major and minor axis ratio $\mathrm{a} / \mathrm{b}=1.5$ of the ellipse. Figure 10 shows that, at the early stage of loading, the tensile strength at the fissure tip of the sandstone sample is not reached due to the low stress level, and the sandstone sample does not show crack propagation. When the model runs to strain $9.44 / 10^{3}$ (point a in Figure 11), before the generation of cracks, compressive stress concentration areas appear at both ends of the major axis of the elliptical hole, the maximum compressive stress is about $70 \mathrm{MPa}$, and the tensile stress is mainly concentrated at both ends of the minor axis of the ellipse and near the vertical fissure (compressive stress is negative and tensile stress is positive), because there is no crack propagation in the sandstone sample at this time, and thus almost no AE occurs. When the model runs to strain $15.31 / 10^{3}$ (point b in Figure 11), cracks are generated first at the upper and lower tips of the vertical fissures and then develop along the axial stress. At this time, the compressive stress concentration area at both ends of the major axis of the ellipse and the tensile stress concentration area near the minor axis of the ellipse and the vertical fissure expand, with the maximum compressive stress reaching $110 \mathrm{MPa}$. The cracks in the specimens expand steadily, and only sporadic $\mathrm{AE}$ occurs, as indicated by the $\mathrm{AE}$ distribution curve. When the model runs to strain $18.86 / 10^{3}$ (point $\mathrm{c}$ in Figure 11), the crack at the fissure tip continues to expand, cracks appear in a local area inside the specimen, and a large number of cracks appear at the left end of the 

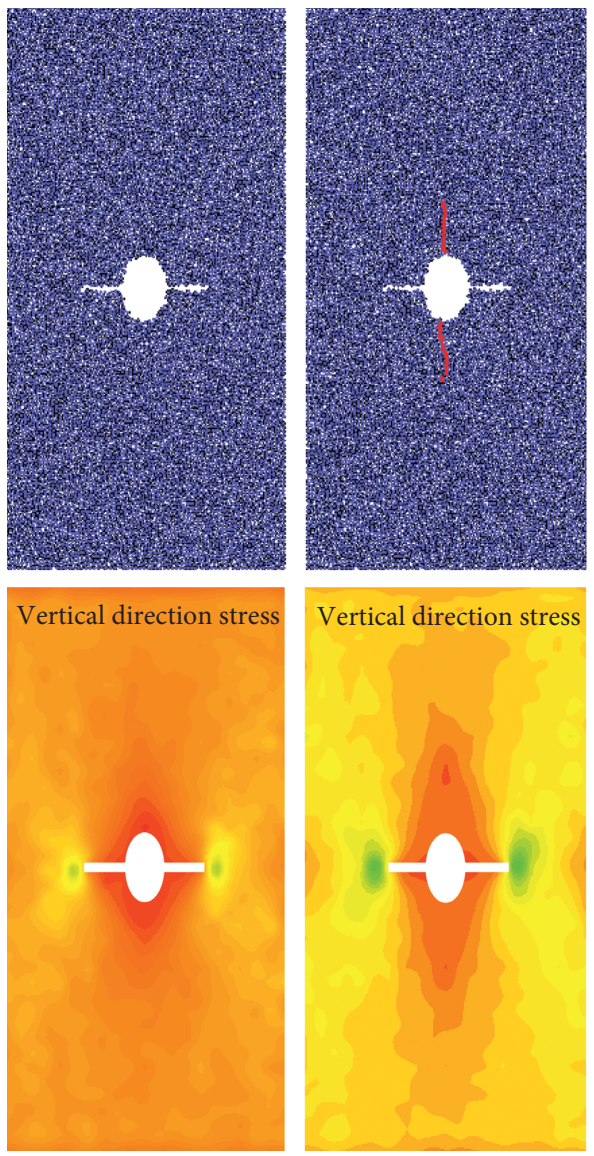

Strain $5.25 / 10^{3}$

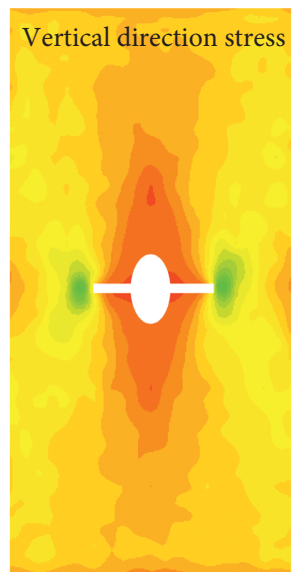

Strain $6.93 / 10^{3}$
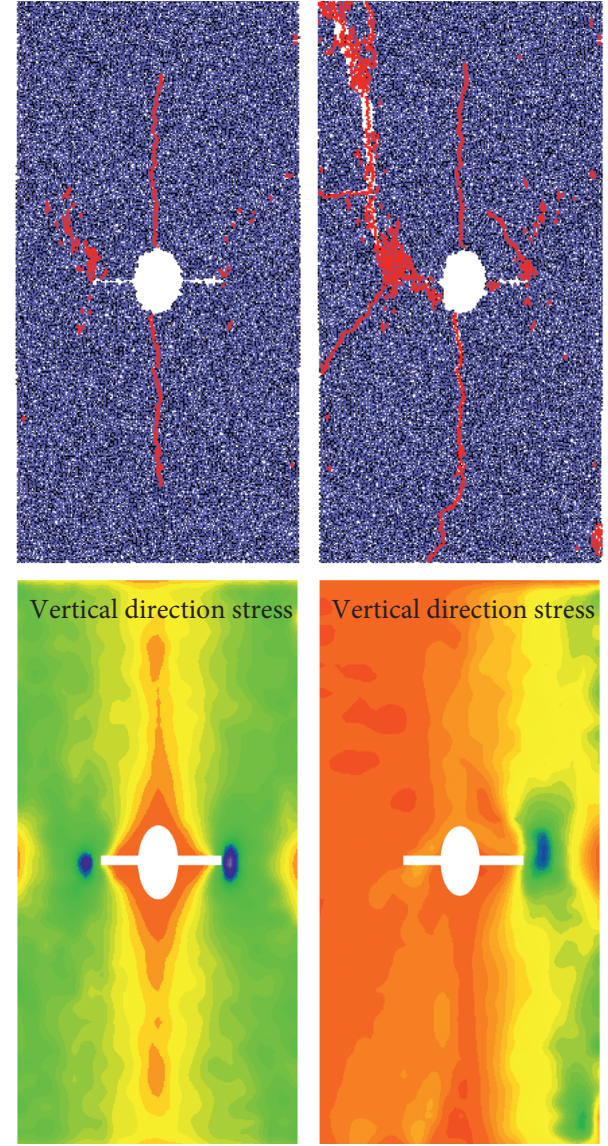

Strain $14.46 / 10^{3}$

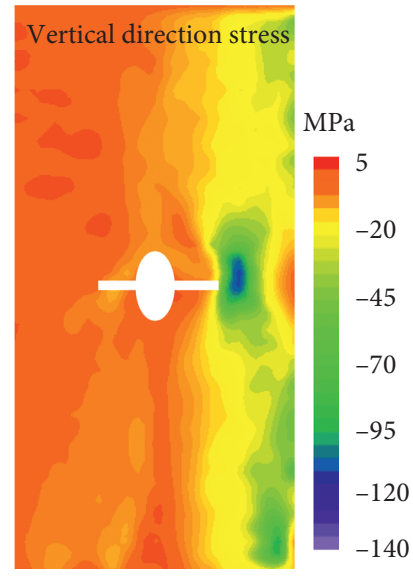

Strain $15.30 / 10^{3}$

FIGURE 12: Crack propagation and maximum principal stress illustration when the major and minor axis ratio a/b=1.5 of horizontal fissure ellipse.

major axis of the ellipse and coalesce the bottom of the specimen, resulting in a large amount of stress release at the right end of the major axis of the ellipse. The compressive stress concentration area is mainly distributed at the left end of the major axis of the ellipse, and the range of tensile stress concentration continues to expand, with the maximum compressive stress reaching $145 \mathrm{MPa}$. At this time, the phenomenon of concentrated AE occurs, mainly because the stress at this stage is close to the peak strength of the sample and local failure phenomenon begins to occur in the sample. When the model runs to strain $19.28 / 10^{3}$ (point $d$ in Figure 11), tensile shear failure occurs with the generation of a large number of cracks in the model, the internal stress of the sample is released significantly, and the maximum compressive stress drops to $115 \mathrm{MPa}$. The compressive stress concentration area is located at the upper left of the sample, and the tensile stress range abruptly expands. The particles inside the sample still have a supporting effect at this time, thus the cracks continue to increase, and AE still presents the phenomenon of centralized generation at this point.

Figures 12 and 13, respectively, show the crack propagation and maximum principal stress evolution illustration, stress-strain curve, and AE-strain curve of the horizontal fissure model when the ratio of major and minor axis of ellipse $a / b=1.5$. When the model runs to strain $5.25 / 10^{3}$ (point a in Figure 13), there is no crack in the sample, and

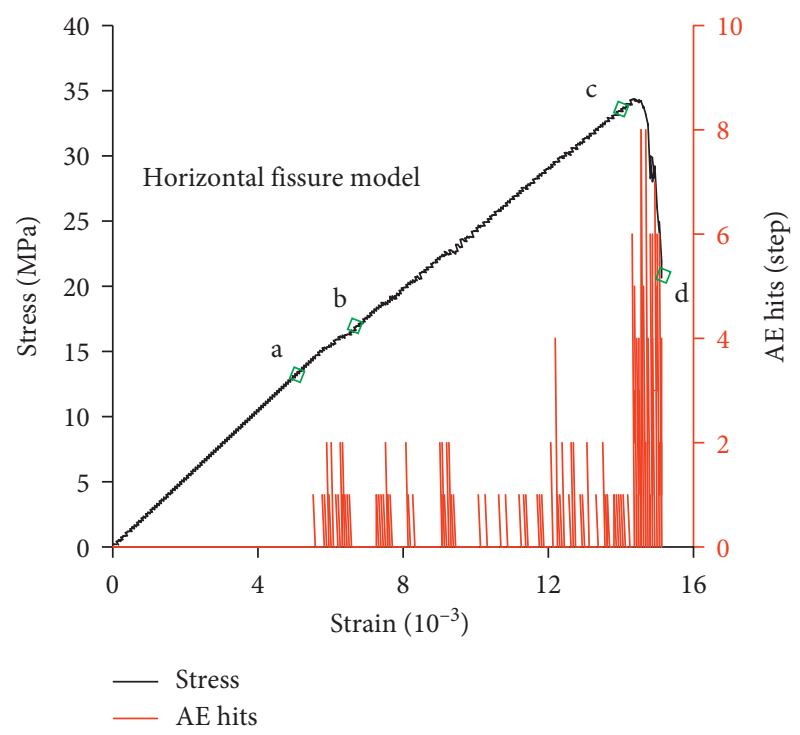

FIgURE 13: Stress-strain curve and acoustic emission-strain curve when the major and minor axis ratio $\mathrm{a} / \mathrm{b}=1.5$ of horizontal fissure ellipse.

compressive stress concentration areas appear at the two ends of the horizontal fissure, with the maximum compressive stress being about $48 \mathrm{MPa}$. Cracks are not 
generated; thus there is almost no AE phenomenon, which is similar to the vertical fissure model in this stage. When the model runs to strain $6.93 / 10^{3}$ (point b in Figure 13), cracks first appear at both ends of the major axis of the ellipse and develop along the axial stress, with the maximum compressive stress being about $70 \mathrm{MP}$. The AE phenomenon at this stage is similar to that of the vertical fissure model, because the cracks in the sample are in the stage of steady expansion. When the model runs to strain $14.46 / 10^{3}$ (point c in Figure 13), cracks at both ends of the major axis of ellipse continue to develop, cracks appear at both ends of the horizontal fissure, and the maximum compressive stress increases to $140 \mathrm{MPa}$. The stress at this stage is close to the peak strength of the sample, and the concentrated local failure phenomenon begins to appear inside the sample and presents the phenomenon of concentrated generation of AE. When the model runs to strain $15.30 / 10^{3}$ (point $d$ in Figure 13), tensile failure occurs in the sample, a large number of cracks are generated, the upper left part of the sample is severely damaged, and the stress is released. Thus, the compressive stress concentration area mainly appears at the right end of the fissure, and the maximum compressive stress is about $120 \mathrm{MPa}$. The sample still has a supporting effect inside at this time; therefore, cracks have always been generated, and the number of AE specimens is still relatively obvious.

In this study, the horizontal fracture model can be regarded as the vertical fracture model by clockwise rotation of $90^{\circ}$. The above-mentioned analysis indicates that the mechanical properties, failure modes, and stress concentration areas before the crack and after the failure of the vertical crack model and the horizontal model are different. Even the mechanical properties and failure of the two models with the same ratio of major and minor axis of ellipse are different. This shows that the arrangement of ellipses and fissure defects significantly influences the mechanical properties and failure characteristics of rocks. The influence of horizontal fissure defect combination on rock mechanical properties is greater than the combination of vertical fissures on rock mechanical properties. This study is based on the analysis of a $2 \mathrm{D}$ uniaxial compression test. The stress of the sample is the force in the vertical direction. Not only does the arrangement of the combination of fissure and defects affect the mechanical properties of the rock, but the direction of the applied force also significantly influences the mechanical properties of the rock.

\section{Conclusion}

(1) The influence of elliptical fissure holes with different ratios of major and minor axis on the mechanical properties of rock was found to be different. The peak strength and elastic modulus of the vertical fissure hole model and horizontal fissure hole model were less than those of the intact rock sample, and the peak strain was greater than that of the intact rock sample, among which the influence of horizontal fissure hole on the rock strength was greater than that of vertical fissure hole on the rock strength. The crack formation of the horizontal fissure hole model preceded the crack formation of the crack fissure hole model.

(2) The failure modes of elliptical fissure holes with different ratios of major and minor axis were divided into the following two types: tensile shear mixed failure and tensile failure. The failure modes of elliptical fissure vertical model with different ratios of major and minor axis and elliptical fissure horizontal model with ratios of major and minor axis of 1.2 and 2.0 were tensile shear mixed failure. Tensile failure occurred when the ratios of major and minor axis of ellipse in the horizontal fissure model were 1, 1.5, and 3.0.

(3) Before crack formation, the tensile stress concentration area was distributed at the upper and lower ends of the axial fissure and the axial elliptical major axis, and the compressive stress concentration area was distributed at both ends of the elliptical major axis and the fissure in the horizontal direction. When the model finally failed, the compressive stress concentration area of the vertical fissure model was distributed on the left side of the fissure hole, and the compressive stress concentration area of the horizontal fissure model was distributed on the right side of the fissure hole.

(4) The cracks in the vertical fissure model and the horizontal fissure model when the ratio of major and minor axis of ellipse was 1.5, were first developed, respectively, along the axial direction at the ends of the fissure and hole, and then secondary cracks occurred at the left and right ends. The maximum compressive stress of each stage of the vertical fissure model was greater than that of the horizontal fissure model. When the model was destroyed, the stress release was also greater. The stress released on the right side of the vertical fissure model and on the left side of the horizontal fissure model was more obvious.

\section{Data Availability}

All data are available within the article or from the corresponding author upon request.

\section{Conflicts of Interest}

The authors declare that there are no conflicts of interest regarding the publication of this paper.

\section{Acknowledgments}

This study was supported by the National Natural Science Foundation of China (51904167, 51474134, and 51774194), Taishan Scholars Project, Taishan Scholar Talent Team Support Plan for Advantaged \& Unique Discipline Areas, Shandong Provincial Natural Science Fund for Distinguished Young Scholars (JQ201612), Shandong Provincial Key Research and Development Plan (2017GSF17112), and 
Project of Open Research Fund for Key Laboratories of Ministry of Education for safe and efficient coal mining (JYBSYS2019201).

\section{References}

[1] Y. H. Li, Z. B. Lin, H. W. Jing et al., "High-accuracy digital speckle correlation method for rock with dynamic fractures," Chinese Journal of Geotechnical Engineering, vol. 34, no. 6, pp. 1060-1069, 2012.

[2] H. W. Jing, H. J. Su, D. L. Yang et al., "Study of strength degradation law of damaged rock sample and its size effect," Chinese Journal of Rock Mechanics and Engineering, vol. 31, no. 3, pp. 543-549, 2012.

[3] M. R. Du, H. G. Jing, and H. J. Su, "Study on the influence of elliptical hole on strength and deformation characteristics of sandstone sample," Journal of Mining \& Safety Engineering, vol. 34, no. 1, pp. 141-147, 2017.

[4] M. Chen, S. Q. Yang, P. G. Ranjith, and Y. C. Zhang, "Cracking behavior of rock containing non-persistent joints with various joints inclinations," Theoretical and Applied Fracture Mechanics, vol. 109, Article ID 102701, 2020.

[5] Q. Z. Guo, H. J. Su, J. W. Liu, Q. Yin, H. J. Jing, and L. Y. Yu, "An experimental study on the fracture behaviors of marble specimens subjected to high temperature treatment," Engineering Fracture Mechanics, vol. 225, Article ID 106862, 2020.

[6] B. Chen, S. C. Zhang, Y. Y. Li, and J. P. Li, "Experimental study on water and sand inrush of mining cracks in loose layers with different clay contents," Bulletin of Engineering Geology and the Environment, vol. 2020, 2020.

[7] H. J. Su, Q. Z. Guo, H. J. Jing, and L. Y. Yu, "Mechanical performances and pore features of coal subjected to heat treatment in approximately vacuum environment," International Journal of Geomechanics, vol. 20, no. 7, 2020.

[8] F. Feng, X. B. Li, K. Du et al., "Comprehensive evaluation of strength criteria for granite, marble, and sandstone based on polyaxial experimental tests," International Journal of Geomechanics, vol. 20, no. 2, Article ID 04019155, 2020.

[9] H. Li and L. N. Y. Wong, "Influence of flaw inclination angle and loading condition on crack initiation and propagation," International Journal of Solids and Structures, vol. 49, no. 18, pp. 2482-2499, 2012.

[10] A. Bobet and H. H. Einstein, "Fracture coalescence in rocktype materials under uniaxial and biaxial compression," International Journal of Rock Mechanics and Mining Sciences, vol. 35, no. 7, pp. 863-888, 1998.

[11] S. Q. Yang, D. S. Yang, H. W. Jing, Y. H. Li, and S. Y. Wang, "An experimental study of the fracture coalescence behaviour of brittle sandstone specimens containing three fissures," Rock Mechanics and Rock Engineering, vol. 45, no. 4, pp. 563-582, 2012.

[12] R.-h. Cao, P. Cao, H. Lin, C.-z. Pu, and K. Ou, "Mechanical behavior of brittle rock-like specimens with pre-existing fissures under uniaxial loading: experimental studies and particle mechanics approach," Rock Mechanics and Rock Engineering, vol. 49, no. 3, pp. 763-783, 2016.

[13] R. H. C. Wong, P. Lin, and C. A. Tang, "Experimental and numerical study on splitting failure of brittle solids containing single pore under uniaxial compression," Mechanics of Materials, vol. 38, no. 1-2, pp. 142-159, 2006.

[14] Y.-H. Huang, S.-Q. Yang, P. G. Ranjith, and J. Zhao, "Strength failure behavior and crack evolution mechanism of granite containing pre-existing non-coplanar holes: experimental study and particle flow modeling," Computers and Geotechnics, vol. 88, pp. 182-198, 2017.

[15] P. Lin, R. H. C. Wong, and C. A. Tang, "Experimental study of coalescence mechanisms and failure under uniaxial compression of granite containing multiple holes," International Journal of Rock Mechanics and Mining Sciences, vol. 77, pp. 313-327, 2015.

[16] S.-Q. Yang, W.-L. Tian, Y.-H. Huang, Z.-G. Ma, L.-F. Fan, and Z.-J. Wu, "Experimental and discrete element modeling on cracking behavior of sandstone containing a single oval flaw under uniaxial compression," Engineering Fracture Mechanics, vol. 194, pp. 154-174, 2018.

[17] Z. Y. Han, D. Y. Li, Q. Q. Zhu, M. Liu, and Z. Sun, "Dynamic fracture evolution and mechanical behavior of sandstone containing noncoplanar elliptical flaws under impact loading," Advances in Civil Engineering, vol. 2018, Article ID 5649357, 16 pages, 2018.

[18] Y. P. Li, L. Z. Chen, and Y. H. Wang, "Experimental research on pre-cracked marble under compression," International Journal of Solids and Structures, vol. 42, no. 9-10, pp. 25052516, 2005.

[19] X.-R. Liu, S.-Q. Yang, Y.-H. Huang, and J.-L. Cheng, "Experimental study on the strength and fracture mechanism of sandstone containing elliptical holes and fissures under uniaxial compression," Engineering Fracture Mechanics, vol. 205, pp. 205-217, 2019.

[20] F. Feng, S. J. Chen, D. Y. Li, S. T. Hu, W. P. Huang, and B. Li, "Analysis of fractures of a hard rock specimen via unloading of central hole with different sectional shapes," Energy Science and Engineering, vol. 7, no. 5, pp. 1-22, 2019.

[21] W. C. Zhu, J. Liu, C. A. Tang, X. D. Zhao, and B. H. Brady, "Simulation of progressive fracturing processes around underground excavations under biaxial compression," Tunnelling and Underground Space Technology, vol. 20, no. 3, pp. 231-247, 2005.

[22] S.-Q. Yang, Y.-H. Huang, W.-L. Tian, and J.-B. Zhu, "An experimental investigation on strength, deformation and crack evolution behavior of sandstone containing two oval flaws under uniaxial compression," Engineering Geology, vol. 217, pp. 35-48, 2017.

[23] Y. P. Li and Y. H. Wang, "Analysis on zigzag cracks in rocklike materials under compression," Acta Mechanica Solida Sinica, vol. 24, pp. 456-462, 2003, in Chinese.

[24] S. Q. Yang, H. W. Jing, and T. Xu, "Mechanical behavior and failure analysis of brittle sandstone specimens containing combined flaws under uniaxial compression," Journal of Central South University, vol. 21, no. 20, pp. 59-73, 2014.

[25] T. Liu, B. Lin, and W. Yang, "Mechanical behavior and failure mechanism of pre-cracked specimen under uniaxial compression," Tectonophysics, vol. 712-713, pp. 330-343, 2017.

[26] P. A. Cundall and O. D. L. Strack, "A discrete numerical model for granular assemblies," Géotechnique, vol. 29, no. 1, pp. 47-65, 1979.

[27] N. Cho, C. D. Martin, and D. C. Sego, "A clumped particle model for rock," International Journal of Rock Mechanics and Mining Sciences, vol. 44, no. 7, pp. 997-1010, 2007.

[28] A. Lisjak and G. Grasselli, "A review of discrete modeling techniques for fracturing processes in discontinuous rock masses," Journal of Rock Mechanics and Geotechnical Engineering, vol. 6, no. 4, pp. 301-314, 2014.

[29] J. F. Hazzard, R. P. Young, and S. C. Maxwell, "Micromechanical modeling of cracking and failure in brittle rocks," Journal of Geophysical Research: Solid Earth, vol. 105, no. B7, pp. 16683-16697, 2000. 
[30] Z. Wen, X. Wang, L. Chen, G. Lin, and H. Zhang, "Size effect on acoustic emission characteristics of coal-rock damage evolution," Advances in Materials Science and Engineering, vol. 2017, Article ID 3472485, 8 pages, 2017.

[31] W. Liu, Z. Yin, A. Yuan, and C. Li, "Particle-discrete-element method-based research on acoustic emission characteristics and energy evolution laws of surrounding rock in different lithologic roadway," Journal of Mining and Safety, vol. 34, no. 2, pp. 363-368, 2017, in Chinese.

[32] H. Su, C. Dang, and Y. Li, "Study of numerical simulation of acoustic emission in rock of inhomogeneity," Rock and Soil Mechanics, vol. 32, no. 6, pp. 1886-1890, 2011, in Chinese.

[33] X. Wang, Z.-j. Wen, and Y.-j. Jiang, "Time-space effect of stress field and damage evolution law of compressed coalrock," Geotechnical and Geological Engineering, vol. 34, no. 6, pp. 1933-1940, 2016. 